\title{
2
}

\section{A quixotic quest? Making theory speak to practice}

David Threlfall and Catherine Althaus

All models are wrong, but some are useful. (George EP Box, as cited in Box, Hunter \& Hunter 2005, p. 440)

This chapter considers the relationship between theory and practice. It seeks to interrogate the historical, professional and ideological underpinnings of theories of the policy process and their utilisation in policy practice. These theories should of course influence practice, but practice should similarly influence theory building. We explore why this connection is commonly seen as unidirectional. To advance both theoretical and practice-based understanding, we argue more attention should be paid to the interconnection of the two. The task of translation from one to the other-in either direction-requires acknowledgement of one's assumptions about knowledge. Knowing how (practice, through experience of public problem-solving, or craft) should be recognised as just as valid as knowing what (academic or scientific knowledge creation and mastery) (Billett 2009 as cited in Cendon 2016, p. 305; cf. Raadschelders 2004). In public policy and public administration, as in many other fields, this has not always been the case-to the point that apparent divisions have arisen between theoretical questions and their practical application. The professional division of labour between academia and policymaking should not naturally hinder mutually reinforcing knowledge advancement in this way. 
Drawing on longstanding debates in educational philosophy about this troubling distinction between theory and practice and applying them to the domain of public policymaking, we urge renewed focus on the interconnection of theory and practice through critical thinking and reflection. Ideally, there should be a two-way translation effect at play in policy learning. For policy professionals, a theory often becomes valuable knowledge only through the experience-in practice-of how to apply it. Likewise, practice should inform theory development through the insights offered by reflection on the experience of practice. We argue this interconnection between practice and theory is possible through a renewed focus on the educational step required to bridge the space 'in-between' theory and practice: encouragement of critical thinking and reflection as a means to learn from and build on experience of practice, and the use of heuristics in policy learning.

In making our argument, we want to be clear that we employ a broad interpretation of the term 'theory'. At times we are referring specifically to the case of theories of the policy process and their deployment, or otherwise, in relation to practice. For many of our arguments, however, we utilise 'theory' to capture the broader concept of academic scholarship. We recognise that empirical work is not the same as theory building and, in this regard, that 'theory' might be misleading. For the purposes of accessibility, however, we think the term 'theory' resonates with how practitioners often understand the breadth of academic efforts. We prefer to embrace this broad church of academic scholarship and see it as encompassing the endeavours of theory building, rather than split hairs on this occasion and risk losing the thread of our analysis and its key messages.

The chapter proceeds in five parts. First, we explore and argue against any perception of a divide between theory and practice in public administration and public policymaking. Reflective learning on policy experience is explored in the second, drawing on educational philosophy. In the third, we analyse public administration theories and theorists for efforts at theoretical consolidation and connection to practice. The role of heuristics in reflective policy learning is fundamental to our own theoretical approach, explored in the fourth part. Finally, in our conclusion, we call for deeper engagement between theorists and practitioners through mutually reinforcing reflective practice, with a view to improving (together) the policymaking process. 


\section{Interrogating the apparent divide between theory and practice}

Many commentators argue that the link between theory and practice in public administration has been afflicted by a deep division or has in some way fundamentally broken down. We remain more optimistic. In fact, we go one step further, and reject outright the existence of any such divide. Promotion of this notion will only (continue to) foster potentially antagonistic relationships rather than encourage the important work of translation and mutual understanding that is so necessary to the advancement of the fields of public policy and public administration in a holistic way.

Scholars such as Sandra Nutley (Nutley et al. 2003), Brian Head (2010, 2014), Paul Cairney (2016), Peter Shergold (2013), Meredith Edwards (2010a, 2010b) and Helen Sullivan (2011, 2019) variously propose that more needs to be done to unite scholarship and practice in the name of improving evidence-informed policymaking. The reasons they identify for the disconnect vary: academia is unplugged from the reality of practice, academic incentives do not value practical impact, practitioners do not have time to read or they cannot access academic information due to paywalls, practitioners perhaps do not comprehend theoretical or academic language and doubt its relevance, practitioners do not appreciate the framing of research questions, practitioners are not interested in rigour or simply fail to apply the lessons of academic work (cf. Buick et al. 2016, p. 36; Newman, Cherney \& Head 2016). The list goes on (and the topic is explored further in the New Zealand context by Karl Löfgren \& Sarah Hendrica Bickerton [this volume, Chapter 5]). While all of these observations contain nuggets of truth, to then interpret their combined pessimistic sentiment into an irreparable gulf, rather than a series of discrete solvable problems, is deeply unhelpful.

In fact, arguments that promote this 'sharp distinction' between theory and practice ensure 'our understanding [of both is] distorted and impaired' (Carr 1986, p. 177). The systematic division of theory and practice artificially separates knowledge from its application and, in doing so, introduces a hierarchy of knowledge based on the division of labour involved in knowledge creation (academia, science) and the application of that knowledge (practice). Writing about this division from the perspective 
of the higher education profession, Carr (1986, p. 177) argued strongly for a break from this technical rational hierarchy, declaring it a hindrance to the advancement of what should be a shared endeavour:

Ideas about the nature of educational theory are always ideas about the nature of educational practice and always incorporate a latent conception of how, in practice, theory should be used. Thus the systematic, well-articulated and explicit accounts of educational theory which philosophers are prone to discuss and dissect are, at one and the same time, less systematic, unarticulated and often implicit accounts of educational practice as well. There are not, therefore, theories of theory and theories of practice and yet other theories about the relationship between the two. All education theories are theories of theory and practice.

By separating philosophical questions about theory from pragmatic discussion of the insights drawn from practice, we may advance theory itself but we lose sight of its connection to context: policy practice happens in an environment that is volatile, complex, uncertain and ambiguous (van der Wal 2017, pp. 1-6). Problems in the real world are not ring-fenced and discrete, as theories might have them be. Real-world puzzles are uncertain and changing continuously, and any application of theory requires an understanding of context, which is generally best achieved through lived experience-and thus through practice (Schön 1983; cf. Cendon 2016, pp. 305-7). Doing this well requires reflection on experience fostered by understanding and judgement-hard won expertise of policymaking and the public administration field (Fletcher et al. 2010, p. 490). What this means is that, in the division of theory from practice, we can de-emphasise the practical importance of real-world problem-solving in favour of a strongly normative approach based on generic and concrete theories. Some theories undoubtedly translate to strong application in a policymaking setting, regardless of context, but this is (unsurprisingly) not universally so.

There is a quote often attributed to Kant that reads: 'theory without practice is empty; practice without theory is blind'. Writing more recently, Langeveld (1979, p. 17, as cited in van Manen, 1996, p. 45) took this further and wrote: 'theory without practice is for geniuses; practice without theory is for fools and rogues. But for the majority of educators, the intimate and unbreakable union of both is necessary.' What is really interesting in Langeveld's contribution is the insertion of educators into the theory-practice paradigm. We similarly believe there is an essential 
yet poorly understood educational step—-through critical thinking and reflection-in bridging any division between theory and practice today. By taking an education and learning approach to the union of theory and practice, we see much room for hope in minimising practical blindness and avoiding theoretical emptiness.

\section{From theory to practice: Knowledge through reflection on experience}

There is, and should be, a fundamental link between knowing and doing, from action to reflection and back again, a point made by Russell Ayres in this volume (Chapter 8). To argue practice is free from theory is either to divorce critical thinking from action, or to overlook the ideological sleight of hand in laying claim to theory-free practice. When put to the test-as Carr (1986) does in his analysis of theories of theory and practice-it becomes clear it is nonsensical to believe that any set of human practices, like any set of human observations, would be free from theoretical preconceptions. In other words, we can all be seen to hold some theory or assumptions about the relationship between theory and practice, whether implicit or explicit. The assumptions themselves are not missing, but rather their conscious or unequivocal recognition. Understood in this light, rival views of policymaking or public administration embed opposing views of how theory relates to practice. Perhaps what critics are bemoaning, then, is the loss of their worldview and its articulation of how theory ought to relate to practice.

While acknowledging that vested interests underlie debates about theory and practice is an important step, the challenge of theoretical and practical advancement remains. Carr (1986, pp. 180-3) sought to solve this problem by categorising four major competing approaches in educational theory and their differing views of practice. He argued through this categorisation that all theory contains an account of practice and all practice embeds theory.

These approaches are:

Common sense: generalisations are acquired through 'observation and analysis of practice and tested pragmatically in practical situations'. Any notion that theory could be developed independently or objectively is rejected; practice establishes the accuracy of theory rather than theory 
establishing soundness of practice. The role of theory is to uncover or recover concepts, principles and skills implicit in 'good' or 'successful' practice, with the arbiter of such practice being the tradition embodied in, and by, revered practitioners in the field in question (in our case, public administration and policymaking).

Applied science: with its focus on behaviourism and scientific standards, this approach sees practice as essentially a technical endeavour designed to bring about particular, specifiable ends. Good practice is determined not by practitioners through some sort of common sense or tradition but by their measurable adherence to higher order scientific principles.

Practical: Practice does not serve fixed ends but is a fluid activity in which choice of both means and ends is guided by values and criteria immanent in the process itself. Theory and good practice, in this approach, neither encourage conformity to a given practice tradition nor scientific prescription. Instead, they encourage attention to the disposition and character of the practitioner as engaged in moral acts. Thus, in our case, public administration and policy practice relies on 'practical wisdom' (Kane \& Patapan 2006) and the informed, committed action and moral judgement of practitioners.

Critical: Theory is meant to help practitioners become self-conscious about the causal determinants of their beliefs and practices, often expressed as ideology, in order to increase their rational autonomy within a social endeavour. This is achieved through 'critical self-reflection' (Carr 1986, p. 183, emphasis added). The stress is on moving not between theory and practice but between irrationality and rationality, and from ignorance and habit to knowledge and reflection.

The common sense and practical approaches articulate a familiar model of public policy learning-on-the-job, through experience of the policymaking process, guided by traditional (common sense) or moral (practical) principles. The technical rational model in the applied science approach sits at the other end of the spectrum, where practice has little to offer. We find the fourth, critical approach promising in assisting the transition from knowing what (theory) to knowing how (practice) and back again. Carr's argument here links directly to the concept of critical thinking and reflective learning in educational philosophy. To expand on this concept and define terms, reflection in this usage follows Cendon (2016, p. 309): 'a critical stance towards [one's] own learning, actual 
situation, and influencing circumstances'. It is 'an evidence-based examination of the sources of and gaps in knowledge and practice, with the intent to improve both' (Ash \& Clayton 2009, pp. 27-8). A shared language with the policy profession is evident in this second quotation, and yet the interlinkage between policy practice and theory on these terms is not. 'We may [then] use existing theories to make further sense of' our policy experiences (van Manen 1991, p. 100, emphasis added). The order that van Manen articulates for the learning process is central to our argument: existing theory supplements experience of practice and reflection on practice. By placing greater weight on this reflective task in policy learning, we should be able to make progress towards a clearer interconnection of theory and practice.

While this may sound like a time-consuming or complex ask, both Carr and van Manen are simply asking for a more conscious approach to learning that values reflection in both theory and practice. Whereas Carr's categorisation identifies the prior assumptions we bring to our thinking about practice, van Manen's (1991, p. 100) model of reflective learning asks practitioners to be critical as they act in the present. For van Manen, insight can be drawn from four levels of reflection: 1) common sense thinking, or intuition and routines; 2) reflection on day-to-day incidents; 3) reflection on one's own experience and the experience of others, or conscious thought to create insights (theories) about action and interaction with others; and 4) reflection on the nature of knowledge, or 'meta-reflection', interrogating the way we think and the way we learn (cf. Cendon 2016, pp. 311-12, 315).

The translation of Carr's and van Manen's work is that policymakers are more influenced by theory than they might believe, and simultaneously more capable of creating sound theory than theorists might expect. While the fast pace or the daily grind of the policy arena may render this task challenging, if we are to advance both theory and practice in a holistic way, practitioners and theorists should be similarly self-critical and reflective, and pursue engagement with one another to exchange these insights. In this way we can develop the most effective theory-informed practice, and successfully tackle the significant translation exercise and effort required to develop practice-informed theory.

There is one further element to add to this discussion of knowledge creation about practice: the concept of emergence, or what we might term the 'Harry Potter maze effect'. In the fourth instalment of this now 
famous book and movie series, Harry Potter and the goblet of fire (Rowling 2000), the by-now teenage wizard, Harry, is selected to compete in the Triwizard Tournament. This is a competition that sets a number of young wizards on a dangerous quest of self-discovery to complete a range of tasks and secure points for their respective wizard schools. The final challenge is to enter a magical maze on the Hogwarts grounds to secure the goal of the Triwizard cup at the centre of the maze. What happens to the wizards after they enter the maze is that it actually shifts around them as they move through it, simultaneously challenging them by revealing their fears and drawing out their courage to confront negative aspects of themselves. As they wade into the maze, not only does the maze change, but also the wizards. They become affected in different ways by the impact of the maze-and their fears and own selves. Thus the wizards become enmeshed in a very dramatic moral dilemma, as they physically move through the maze and simultaneously engage with decisions as to how to respond to their shifting feelings and decisions.

Lessons from the world of practice tell us that, in a similar vein, it is oftentimes very bewildering navigating the maze of policymaking life. There are two basic responses when we find ourselves affected by this kind of complexity: one is to be bewildered and seek out sense-making tools to bring order to the analytical task and to the gathering of evidence and potential solutions. We might call this the closed mode of rational evidence gathering and analysis. The other route is to be more creative and secure mechanisms that foster innovation and help develop new ways to frame policy challenges, including new narratives or meta-values that might encourage diverse communities to break through impasses (such as how to define problems and reimagine what solutions might be possible for them). We might call this the open mode of craft and creativity. Both closed and open modes are important and of value to the policymaking endeavour, but they involve dissimilar processes and embed different philosophies and goals. They speak to a variety of ways that the literature, too, explains how to do public administration and policymaking (the art, craft or science debate explored by Raadschelders (2004) provides a good introduction).

The maze metaphor captures an important point about theory and practice — as you are engaging in different ways of looking at policymaking and public administration, you are simultaneously changing yourself and policymaking as you perform this policy work. The processes of thinking and doing policy are unavoidably intertwined and reflexive. 


\section{Theory and practice in public policy and public administration}

We have argued that policy learners must be reflective and critical practitioners if they are to succeed. As such, the wide array of policy models, frameworks and theories that exist in academic literature should be a boon for practitioners (a brief study of recent additions includes Althaus, Bridgman \& Davis 2018; Birkland 2016; Colebatch 2009; Dye 2007; Gerston 2010; Haigh 2012; Head \& Crowley 2015; John 2012; Knill \& Tosun 2012; Kraft \& Furlong 2013; Pal 2014; Sabatier \& Weible 2014; Scott \& Baehler 2010; Wilson 2016). While at times underutilised or misunderstood, these resources are at practitioners' disposal—and it should not require magic to turn their insights into practical benefit. Similarly, practitioner insights and experiences offer tremendous encouragement towards improvements in policymaking processes and outcomes, feeding the development and testing of new ideas by theorists and prompting policymakers to deliberate reflectively on assumptions, values and priorities.

Elinor Ostrom (1999, pp. 39-41) provides a valuable contribution by distinguishing between frameworks, theories and models (cf. Schlager 1999). These conceptual terms operate on three descending and increasingly detailed levels of abstraction. At the most general level, frameworks set the architecture for analysis and comparison of identified concepts. Theories set out propositions about the relationships between those concepts. Models then make specific assumptions about the operation of elements, structures or outcomes within the broader explanatory framework. 'Several theories are usually compatible with any framework ... [and multiple] models are compatible with most theories' (Ostrom 1999, p. 40). Many theories in particular attempt to establish causality, explanation or prediction. That these are measures of theoretical strength favoured by many academics underlines that most theories emphasise an academic perspective, highlighting in particular the complexity of policymaking. For practitioners, the risk is that, in highlighting complexity, we forget the connection to the object of study, that is, policy practice, not just understanding of it. Practice demands action, even in the face of complexity. 
For example, Paul Cairney and Paul Sabatier both focus on the comparison and advancement of theories (Cairney \& Heikkila 2014; Sabatier 1999b). In Sabatier's writing, in particular, scholars are the sole audience; there is little emphasis on practitioners. Instead, we read of the 'analyst' or the 'observer' (Sabatier 1999a, p. 4). Cairney (2015; Cairney \& Oliver 2018) is more aware of the domain of practice, but the direction of knowledge creation in his writing is from academic insight to practical application. If we were to map this academic inclination to Carr's categorisation described earlier, we might say that the implicit assumption about practice in such writing aligns best with the applied science approach: a hierarchy whereby scientific knowledge is valued above practical experience and problem-solving. With knowledge use and application so divided, the task of thinking through and advancing connection to practice remains incomplete. The reflection encouraged by van Manen is not yet leveraged let alone optimised.

There is nevertheless a strong vein of public policy and public administration literature devoted to holistic theoretical consolidation and advancement. Authors such as Cairney (2013) and Graham Allison (1971) speak of the value brought by applying different lenses to the scholarship of public administration and policymaking. Cairney (2013) suggests three possible approaches for combining theories (or aspects thereof): synthesis, contradiction and complementarity. Members of the complementary camp support the use of different theories to gain breadth of insight, seeing multiplicity of views as both helpful and desirable. Synthesisers, meanwhile, believe that a grand theory is both desirable and attainable through a combination of the array of models, frameworks and theories on offer. The contradictory approach is perhaps better termed comparison-the contribution of each theory and its assumptions are compared, and the most useful theory selected over others, in a 'policy shootout' (Cairney 2015, p. 10).

To us, it seems pointless and self-defeating to pit different theories against each other in this way. We sit squarely in Cairney's complementary camp. Putting our practitioner hats on, and acknowledging the myriad structural, resource and political challenges of the policy world, we see similarities between, and diverse application possibilities for, the widest range of theories, models and frameworks. We believe practitioners are comfortable with complexity and that they can apply whatever model helps them to understand their task more clearly in order to leverage processes and institutions for a better policy outcome. As theorists, this 
means understanding the underlying assumptions of our own standpoint and interrogating how we can contribute to practical knowledge as well. Thus, as theorists, we believe that we should not discard theoretical advancement as an act in itself, given it offers a means to inspire potential innovation or improved practice.

This position promotes a more conscious view of where we sit in relation to Carr's categorisation of approaches to the intertwining of theory and practice. Complementarity advocates would support a diversity of approaches whereas synthesisers and those in favour of contradiction are more likely to sit within the applied science or common sense approach. In his conclusion, Cairney (2013, pp. 14-15) argues that we generally share a desire to advance theories of policymaking, but disagree as to the methodology that will allow us to do so. From the standpoint of building academic knowledge of policymaking, it is hard to argue against his first recommendation (pp. 15-16) for acceptance of 'methodological pluralism' and 'sophistication', supported by 'interdisciplinary collaboration'. However, from the standpoint of impact on practice, there is a translation effort lacking even in this liberal approach. How do we make the jump to practical application?

\section{From knowing what to knowing how: The policy cycle and the role of heuristics}

The policy cycle has been much maligned in public policy and public administration theory. Yet, Lasswell's (1956) core idea—a staged process through which policy issues progress, and a means to analyse each stageremains an important contribution. It 'offer[s] a way to think about public policy in concept and, just as important, in operation' (deLeon 1999 , p. 20). It sharpens focus on policy problems and the way they work through policy systems, and promotes a multidisciplinary approach to policy problem-solving (Althaus, Bridgman \& Davis 2018).

The key point made by critiques of the cycle is that it is an oversimplification-that policymaking is always more complex and does not work in a linear fashion (deLeon 1999; cf. Jenkins-Smith \& Sabatier 1993, pp. 3-4; Colebatch 2006). We argue that this criticism misses the point. Neither theorists nor practitioners are looking for an elegant solution with something like the policy cycle. In fact, we believe 
the very reason practitioners find value in the policy cycle, and the core reason for its longevity, lies in the simplicity of its message and the ease with which it is taught. The policy cycle is a learning aid, or heuristic, a 'process or method' by which someone can 'discover or learn something for themselves' (Oxford Dictionaries 2019). As a heuristic, the policy cycle serves to prompt reflection on prior experience of practice and offers a framework for learning about future experience (see e.g. the arguments and application of Meredith Edwards and Russell Ayres in Chapters 7 and 8, respectively). It allows practitioners to step back from the complicated work of the day-to-day policy world with the aid of a framework that they can internalise, learn from and then work with (often unconsciously) in the future.

This is particularly what motivated the development of the Australian policy cycle as a specific interpretation of Lasswell's staged policy process. Figure 2.1 provides a visual of the Australian policy cycle conveying the cyclical and interconnected nature of the various steps. The text associated with the Australian model deliberately conveys its heuristic nature and the proactive and reflective contributions needed from practitioners to bring its application alive and fruitful for policymaking outcomes.

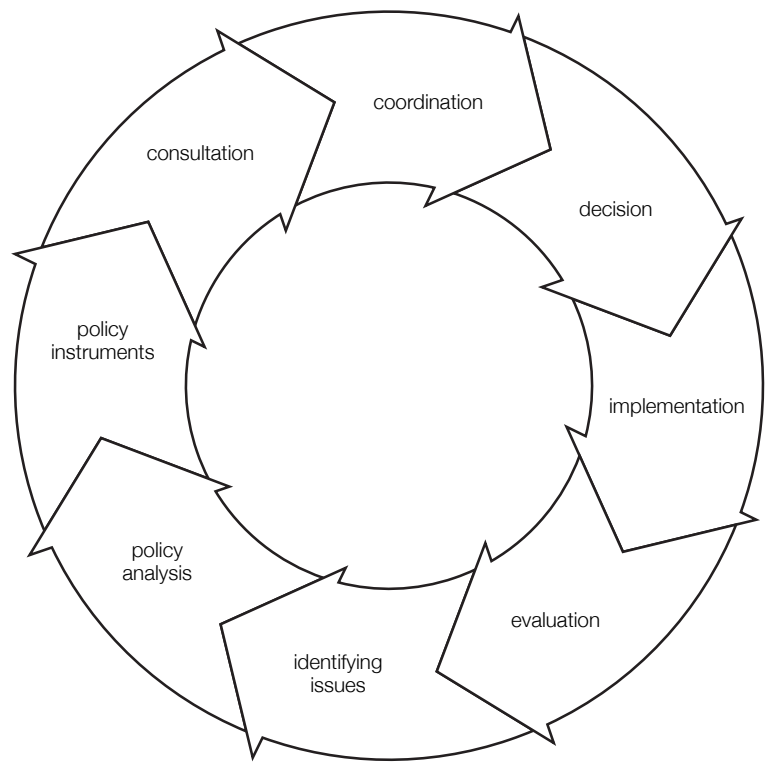

Figure 2.1. The Australian policy cycle.

Source: Althaus, Bridgman and Davis (2018). 
Essentially, we are following the Harry Potter maze metaphor-theory and practice are emergent, and policy and public administration protagonists are pivotal as active agents of change. Both policymakers and theorists, as well as policy itself, shift and change as we engage in thinking about policy and making policy. In this fluid environment, a heuristic serves as a guide for those who need to learn about the challenges of their roles. Seen in this light, then, the policy cycle is focused on the teaching, learning and reflection process. It provides a means to make sense of experience, as well as a tool to inspire creativity as policymakers navigate the policy maze they inevitably confront.

A useful analogy here is the London underground (the 'tube'). London in real-life or on a map does not look like the tube map does. Instead, the tube map is a heuristic to help us navigate from one place to another. It is deeply practical; it gets you from A to B. It is not to scale, nor is it physically or geographically accurate, but it can be helpful to travellers. The policy cycle and other heuristics serve the same purpose. Heuristics work because they focus on putting theory and practice at the service of one another, rather than in opposition. They focus on reflective and reflexive learning, and turning knowledge into application in practice. We might argue that a heuristic like the policy cycle is the step from pedagogy (the method and practice of teaching) to andragogy (the method and practice of teaching adult learners) (Knowles 1984). Thinking through this interconnection between the theory of practice and the teaching of practice is vitally important in ensuring policy learning continues to improve in future.

As a learning tool, the policy cycle articulates an approach to solving public policy 'puzzles' on both systemic and process levels. It also sets the routines of policy work for practitioners, a critical element of the governance process (Davis 1995). Cendon (2016, p. 318) writes that a 'central contribution of teachers is supporting the handling of routines, patterns, or assumptions students have developed as "inner and outer framework conditions". Inner framework conditions should be understood as personal biases that may hinder learning or action in new environments, while outer framework conditions are the elements of the public sector that may or may not be susceptible to change. The task of the teacher (or the policy cycle) is to help practitioners learning their craft to understand what they must change in themselves, what can change around them and what cannot. In understanding these routines and the reality of the confines of their environment, they understand how to direct their efforts for maximum impact. The combination of a heuristic like the policy cycle 
(a tool for at first conscious but increasingly implicit action) and the idea of reflective learning (a very conscious act) leads to a continuum of thought-informed practice that both incorporates theory and is cognisant of the realities of practice. We can map this onto Donald Schön's (1983) distinction between knowing in action (at times unconscious yet clearly thought-informed action, like intuition and implicit knowledge-the 'main characteristics [of which] are routines'); reflection in action, more conscious yet immediate thought during practice; and reflection on action, or 'systematic and critical review and continuous development of one's practice' after the fact (Cendon 2016, p. 307).

Perhaps, then, the best approach to the use of the policy cycle is to acknowledge its strength in assisting practical learning, and to build on its theoretical weaknesses with a view to consolidation rather than competition. Howlett, McConnell and Perl (2017) make just such a contribution to 'moving policy theory forward' in their synthesis of the policy cycle with the multiple streams and advocacy coalition frameworks of Kingdon (1984) and Sabatier and Jenkins-Smith (1993), respectively. By bringing together the insights of three parallel approaches, we derive a richer analysis within the stages of the cycle, with a clearer view of the actors and forces at play in the policy process.

The task of connecting theory to practice is clearly complicated. However, through its careful application as a heuristic, the policy cycle is able to tap both the technocratic closed mode of analysis and evidence gathering, underpinned by the rational-comprehensive approach to policymaking, and also the open mode recourse to practitioner application and judgement. The heuristic embedded in the policy cycle embraces and deploys many of the adult learning principles outlined above. It encourages practitioners and theorists to be pluralistic, active, intrinsically motivated, goal oriented and somewhat pragmatic in how they apply judgement to particular circumstances as well as develop more generalist principles drawn from experience. A key point in our discussion of the cycle is that practitioners and theorists have freedom and should be supported to exercise their own initiative and creativity to progress the discipline as well as societal outcomes. For us, the point of the policy cycle is to spur improvement of practice, a goal far removed from militant argument on the relative merits of different research paradigms. 


\section{Conclusion}

This chapter has explored and argued against the existence of a theorypractice divide in public administration and public policymaking. There is no value in perpetuating belief in, or perceptions of, a divide. Rather, we should pursue the interconnection of theory and practice in order to advance knowledge and improve practice for those working in either domain. We draw on education philosophy and reflective learning on policy experience to make this case. A brief overview and analysis of public administration theories and theorists indicates various attempts at theoretical consolidation and connection to practice; however, these attempts often perpetuate a hierarchy of knowledge generation from academia into practice. If we are to move to a position whereby both fields are self-reinforcing, this implicit hierarchy would no longer exist or assumptions about the relationship/s between theory and practice would be made transparent.

While it is natural that there may be a certain division of labour and specialisation for academics and policy professionals, those working in both fields must possess a shared language and desire to critique, learn and reflect together with a view to improving the policymaking process and outcomes. This two-way task of translation and knowledge creation is vital. Theory building and practice improvement are a shared enterprise. The more we can promote this joint enterprise, and the more we encourage both parties to exercise their agency, the better for policy processes and outcomes.

One way of stimulating this interconnection and reflective practice is through heuristics. We argue that a turn to education and its tools (such as heuristics) is beneficial for both policy practitioners and scholars committed to the improvement of practice. As Box (Box, Hunter \& Hunter 2005, p. 440) argues in our epigraph, no single heuristic captures the true operation of policy processes or political systems. Nor should it. Rather, the intent and benefit is to cut through a perfect description or an accurate prediction in order to assist in the task of learning and doing that policy practitioners face on a daily basis. This makes for truly reflective practice for scholars and practitioners. We hope this assessment of the field might inspire others equally to join this endeavour. 


\section{References}

Allison, G 1971, Essence of decision: Explaining the Cuban missile crisis, Little Brown, Boston, MA.

Althaus, C, Bridgman, P \& Davis, G 2018, The Australian policy handbook: A practical guide to the policy-making process, 6th edn, Allen \& Unwin, Crows Nest, NSW.

Ash, SL \& Clayton, PH 2009, 'Generating, deepening, and documenting learning: The power of critical reflection in applied learning', Journal of Applied Learning in Higher Education, vol. 1, pp. 25-48.

Billett, S 2009, 'Realising the educational worth of integrating work experiences in higher education', Studies in Higher Education, vol. 34, no. 7, pp. 827-43, doi.org/10.1080/03075070802706561.

Birkland, TA 2016, An introduction to the policy process: Theories, concepts and models of public policy making, 4th edn, Routledge, New York, NY, doi.org/10.4324/ 9781315717371.

Box, GEP, Hunter, W \& Hunter, S 2005, Statistics for experimenters: Design, innovation, and discovery, 2nd edn, Wiley, New York, NY.

Buick, F, Blackman, D, O’Flynn, J, O’Donnell, M \& West, D 2016, 'Effective practitioner-scholar relationships: Lessons from a coproduction partnership', Public Administration Review, vol. 76, no. 1, pp. 35-47, doi.org/10.1111/ puar. 12481 .

Cairney, P 2013, 'Standing on the shoulders of giants: How do we combine the insights of multiple theories in public policy studies?', Policy Studies Journal, vol. 41, no. 1, p. 21, doi.org/10.1111/psj.12000.

Cairney, P 2015, 'How can policy theory have an impact on policymaking? The role of theory-led academic-practitioner discussions', Teaching Public Administration,vol.33, no. 1,pp.22-39, doi.org/10.1177/0144739414532284.

Cairney, P 2016, The politics of evidence-based policy making, Palgrave Macmillan, London, UK.

Cairney, P \& Heikkila, T 2014, 'A comparison of theories of the policy process', in PA Sabatier \& CM Weible (eds), Theories of the policy process, Westview Press, Boulder, CO.

Cairney, P \& Oliver, K 2018, 'How should academics engage in policymaking to achieve impact?', Political Studies Review, vol. [Special Is.], pp. 1-17, doi.org/ $10.1177 / 1478929918807714$. 
Carr, W 1986, 'Theories of theory and practice', Journal of Philosophy of Education, vol. 20, no. 2, pp. 177-86, doi.org/10.1111/j.1467-9752.1986.tb00125.x.

Cendon, E 2016, 'Bridging theory and practice: Reflective learning in higher education', in W Nuninger \& J-M Châtelet (eds), Handbook of research on quality assurance and value management in higher education, IGI Global, Pennsylvania, pp. 304-24, doi.org/10.4018/978-1-5225-0024-7.ch012.

Colebatch, HK (ed.) 2006, Beyond the policy cycle: The policy process in Australia, Allen \& Unwin, Sydney, NSW.

Colebatch, HK 2009, Policy, 3rd edn, Open University Press, Maidenhead, UK.

Davis, G 1995, A government of routines: Executive coordination in an Australian state, Macmillan Education Australia, South Melbourne, Vic.

DeLeon, P 1999, 'The stages approach to the policy process: What has it done? Where is it going?', in PA Sabatier (ed.), Theories of the policy process, Westview Press, Boulder CO.

Dye, T 2007, Understanding public policy, 12th edn, Prentice-Hall, Upper Saddle River, NJ.

Edwards, M 2010a, 'In search of useful research: Demand and supply challenges for policy makers', Public Administration Today, no. 24, pp. 56-64.

Edwards, M 2010b, 'Making research more relevant to policy: Evidence and suggestions', in G Bammer, A Michaux \& A Sanson (eds), Bridging the 'know-do' gap: Knowledge brokering to improve child wellbeing, ANU E Press, Canberra, ACT. doi.org/10.22459/BKDG.08.2010.04.

Fletcher, M, Zuber-Skerritt, O, Bartlett, B, Albertyn, R \& Kearney, J 2010, 'Meta-action research on a leadership development program: A process model for life-long learning', Systemic Practice \& Action Research, vol. 23, no. 6, pp. 487-507, doi.org/10.1007/s11213-010-9173-5.

Gerston, L 2010, Public policy making: Process and principles, 3rd edn, ME Sharpe, Armonk, NY.

Haigh, Y 2012, Public policy in Australia: Theory and practice, Oxford University Press, Melbourne, Vic.

Head, BW 2010, 'From knowledge transfer to knowledge sharing? Towards better links between research, policy and practice', in G Bammer, A Michaux \& A Sanson (eds), Bridging the 'know-do' gap: Knowledge brokering to improve child wellbeing, ANU E Press, Canberra, ACT, doi.org/10.22459/ BKDG.08.2010.08. 
Head, BW 2014, 'The collaboration solution? Factors for collaborative success', in J O'Flynn, D Blackman \& J Halligan (eds), Crossing boundaries in public management and policy: The international experience, Routledge, Abingdon, UK.

Head, B and Crowley, K (eds) 2015, Policy analysis in Australia, Policy Press, Bristol, UK, doi.org/10.1332/policypress/9781447310273.001.0001.

Howlett, M, McConnell, A \& Perl, A 2017, 'Moving policy theory forward: Connecting multiple stream and advocacy coalition frameworks to policy cycle models of analysis', Australian Journal of Public Administration, vol. 76, no. 1, pp. 65-79, doi.org/10.1111/1467-8500.12191.

Jenkins-Smith, HC \& Sabatier, PA 1993, 'The study of the public policy process', in PA Sabatier \& HC Jenkins-Smith (eds), Policy change and learning: An advocacy coalition approach, Westview Press, Boulder, CO.

John, P 2012, Analyzing public policy, 2nd edn, Routledge, Abingdon, UK, doi.org/10.4324/9780203136218.

Kane, J \& Patapan, H 2006, 'In search of prudence: The hidden problem of managerial reform', Public Administration Review, vol. 66, no. 5, pp. 711-24, doi.org/10.1111/j.1540-6210.2006.00636.x.

Kingdon, JW 1984, Agendas, alternatives and public policies, Little, Brown and Company, Boston, MA.

Knill, C \& Tosun, J 2012, Public policy: A new introduction, Palgrave Macmillan, Basingstoke, UK.

Knowles, MS 1984, Andragogy in action: Applying modern principles of adult learning, Jossey-Bass, San Francisco, CA.

Kraft, ME \& Furlong, SR 2013, Public policy: Politics, analysis and alternatives, 4th edn, Sage, Thousand Oaks, CA.

Lasswell, HD 1956, The decision process: Seven categories of functional analysis, University of Maryland Press, College Park, MD.

Newman, J, Cherney, A \& Head, BW 2016, 'Do policy makers use academic research? Reexamining the "two communities" theory of research utilization', Public Administration Review, vol. 76, no. 1, pp. 24-32, doi.org/10.1111/ puar. 12464 .

Nutley, S, Walter, I \& Davies, HTO 2003, 'From knowing to doing: A framework for understanding the evidence-into-practice agenda', Evaluation, vol. 9, no. 2, pp. 125-48, doi.org/10.1177/1356389003009002002. 
Ostrom, E 1999, 'Institutional rational choice: An assessment of the institutional analysis and development framework', in PA Sabatier (ed.), Theories of the policy process, Westview Press, Boulder, CO.

Oxford Dictionaries 2019, 'Heuristic', British \& World English online, viewed 18 March 2019, en.oxforddictionaries.com/definition/heuristic.

Pal, L 2014, Beyond policy analysis: Public issue management in turbulent times, 5 th edn, Nelson Education, Toronto, Canada.

Raadschelders, JCN 2004, 'A model of the arena of PA-theory: Bogey man, doctor's bag and/or artist's medium', Administrative Theory \& Praxis, vol. 26, no. 1, pp. 46-78, doi.org/10.1080/10841806.2004.11029430.

Rowling, JK 2000, Harry Potter and the goblet of fire, Bloomsbury, London, UK.

Sabatier, PA 1999a, 'The need for better theories', in PA Sabatier (ed.), Theories of the policy process, Westview Press, Boulder, CO.

Sabatier, PA (ed.) 1999b, Theories of the policy process, Westview Press, Boulder, CO.

Sabatier, PA \& Jenkins-Smith, HC (eds) 1993, Policy change and learning: An advocacy coalition approach, Westview Press, Boulder, CO.

Sabatier, PA \& Weible, C (eds) 2014, Theories of the policy process: Theoretical lenses on public policy, 3rd edn, Westview Press, Boulder, CO.

Schlager, E 1999, 'A comparison of frameworks, theories, and models of policy processes', in PA Sabatier (ed.), Theories of the policy process, Westview Press, Boulder, CO.

Schön, DA 1983, The reflective practitioner: How professionals think in action, Basic Books, New York, NY.

Scott, S \& Baehler, K 2010, Adding value to policy analysis and advice, UNSW Press, Sydney, NSW.

Shergold, P 2013, 'Why economists succeed (or fail) to influence policy', Policy: A Journal of Public Policy and Ideas, vol. 29, no. 1, pp. 16-20.

Sullivan, H2011, “'Truth” junkies: Using evaluation in UKpublic policy', Policyand Politics, vol. 39, no. 4, pp. 499-512, doi.org/10.1332/030557311X574216.

Sullivan, H 2019, 'Building a knowledge-sharing system: Innovation, replication, co-production and trust-a response', Australian Journal of Public Administration, vol. 78, no. 2. pp. 319-21, doi.org/10.1111/1467-8500.12370. 
van der Wal, Z 2017, The 21st century public manager: Challenges, people and strategies, Palgrave Macmillan, London, UK.

van Manen, M 1991, The tact of teaching: The meaning of pedagogical thoughtfulness, Althouse Press, London, UK.

van Manen, M 1996, 'Phenomenological pedagogy and the question of meaning', in D Vandenberg (ed), Phenomenology and educational discourse, Heinemann Higher and Further Education, Durban, South Africa.

Wilson, RC Jr 2016, Rethinking public administration: The case for management, 2nd edn, Melvin \& Leigh, Irvine, CA. 
This text is taken from Learning Policy, Doing Policy: Interactions Between Public Policy Theory, Practice and Teaching, edited by Trish Mercer, Russell Ayres, Brian Head and John Wanna, published 2021 by ANU Press, The Australian National University, Canberra, Australia.

doi.org/10.22459/LPDP.2021.02 